\title{
An ergonomics approach to citrus harvest mechanization
}

\author{
Simone Emmanuelle Alves Costa ${ }^{\mathrm{a},}$ and João Alberto Camarotto ${ }^{\mathrm{a}}$ \\ ${ }^{a}$ Department of Production Engineering, Federal University of Sao Carlos, Washington Luiz, km 235,13565-905, \\ Sao Carlos/SP, Brazil
}

\begin{abstract}
Due to the increase of production costs in manual harvesting, strategies must be developed in order to overcome these effects, such as the attempts in implementing agricultural machines in harvest activities, whether being totally or partially mechanized. This study brings a qualitative and quantitative comparison on the impacts in work conditions and productivity in Brazilian orchards caused by the use of semi-mechanized harvesting systems, such as multiplatforms. The results come from the application of Ergonomic Work Analysis method, which focuses in the activity, quantifying and analyzing times and frequencies of the harvesting cycle, as well as the amount of movements. To achieve this, footage, interviews and a stopwatch were used in the observation 12 pickers' work cycles, six for each method of harvesting. The data interpretation pointed to improvement in working conditions with a reduction in the amount of movements performed by the picker, and increase of up to $60 \%$ in productivity with the use of semi-mechanized harvesting. Thus, the found results indicate the viability of this harvesting method. However, other variables must be observed in future studies in order to complete the guidelines for a healthy progress in the area of citrus harvesting in Brazil.
\end{abstract}

Keywords: orange culture, worker health, productivity, orange picker, analyses of activity

\section{Introduction}

The citrus fruit market in Brazil generates about 400 thousand direct jobs and roughly a million people are involved in this sector if the indirect jobs created are taken into consideration $[9,10]$.

According to studies $[5,6]$, manpower represents the greatest citrus-harvesting cost ratio, with expenditures of about 106 million dollars/annually, which represents $44 \%$ of the total citrus production costs. The companies then foresee a substantial cost reduction potential for this task by developing methods that increase harvesting efficiency.

Initiatives linked to the mechanization process of harvesting are being tested in Brazilian orchards. Their implementation is still uncertain due to the difficulty of adapting to the orchards and conciliating the high productivity rate and harvested fruit quality, without undermining the next crop.

Therefore manual harvesting continues as the most widely used technique in most domestic citrus properties, as the fruits removed from the tree exhibit high quality, which is the main advantage over the existing mechanical techniques [6].

Despite this advantage, the cost of manual harvesting has been continuously increasing with a drop in the productivity. Furthermore, this harvesting method requires strenuous physical effort, with a high risk of accidents, which makes the work process more expensive with work-related expenditures, and derails its continuity as the primary harvesting method.

The use of multi-use lifting platforms appears as an alternative to the total mechanization of harvesting, characterized as only a helping device to the fruit picker, intended to maintain the fruit selection level and to increase productivity. Studies have shown that there might be an increment in the harvesting productivity, with data indicating an increase of $40 \%[3,11]$.

However, efforts have to be done not to increase work-related intensity and intensification. Once the degree of physical expenditure has not been considered in those studies and little is known about the consequences in the picker's work conditions.

The causes for the increase in work intensity and intensification are connected to the policy of reduc-

\footnotetext{
* Corresponding author. E-mail: editorial@iospress.nl. Check if the checkbox in menu Tools/Options/Compatibility/Lay out footnotes like Word 6. $x / 95 / 97$ is selected if you make a footnote for the corresponding author.
} 
ing the number of employees, accelerated production pace, reduced working hours while maintaining the same production, multiple functions and work productivity. These are factors usually found when devices and technologies in production are used.

This study aims to evaluate the manual harvesting labor and its implications in workers' health, as well as the impact of the use of lifting platforms in productivity and work conditions of Brazilian citrus pickers.

\section{Materials and methods}

The work-related situations in question were studied through field work using the Ergonomic Work Analysis method, which aims to produce increasing knowledge and establish an operative diagnosis over the situation. The operative term refers to the need for the analysis process to indicate effective actions, in order to overcome the initial conditions found and to consolidate positive changes in health and productivity indicators.

Thus, quantitative and qualitative analyses were conducted by comparing the manual and semimechanized harvesting operations to expose the advantages and disadvantages from the productivity point of view, and the effects on the picker's health. The analysis included the study of harvesting time and methods, tasks repeatability and amount of movements made, in order to provide indicators about such harvesting procedures, which could offer comfort and safety to orange pickers during their work.

Five visits to the farms from the Midwest region of São Paulo state were carried out. The plant groups studied belonged to the Hamlin variety, which concentrates the fruit at the bottom of the plant and has a mean production rate of four boxes of $27.2 \mathrm{~kg} /$ tree.

For the comparison between the cycle times of both harvesting methods, a stopwatch was used and the six pickers were filmed. For each of the methods three counts of the cycle were performed, as well as recording the average times for each crop stage.

The cycles were divided into stages to facilitate the analysis among the different methods. The harvesting cycle was divided into six stages: Picking fruits from a ladder, picking fruits without a ladder, unloading the bag, moving the ladder, picking from the ground and moving to another tree.

The semi-mechanized harvesting cycle was divided into seven stages: Picking on the platform, picking with a hook, emptying the boxes on the conveyor belt, moving the platform, picking at the bottom, unloading the bag, replacing the canvas bin.

The semi-mechanized system, also known as a picking aid device, contains four platforms moved by hydraulic arms and a fruit outflow mechanism composed of: outflow drains, two metal boxes in each device and a conveyor belt. The platforms move in the vertical axis and reach the two highest levels of the tree, the top and the middle one, demanding other workers to harvest the bottom.

Regarding the quantification of postures and movements, four cycles of each method were observed, reported and classified. For this, postures and movements in the cycles were divided in four categories of movements and postures in the cycles, according to the definition of dynamic and static postures [8]; and the definition of awkward postures and griprelated muscles proposed [7]:

a) Dynamic Postures: rotating motions in short intervals (less than one minute), using different muscle groups.

b) Static Postures: muscular contraction maintained in a period of time exceeding one minute.

c) Awkward Postures: postures close to the limit of the joint range movement.

d) Use of grip-related muscles: the use of muscles where there is a narrow synovial sheath, subjected to a high repeatability and friction on the structures.

The productivity on the sample population is on average three to five bins/day. The bin is a flexible container made of canvas, used to store the produce, with a $550 \mathrm{~kg}$ capacity, or 20 boxes of $27.2 \mathrm{~kg}$, a measurement used to calculate the harvesting productivity.

All pickers were males from the State of Piaui, Northeast Brazil. The workday was of eight hours, discounting one hour for lunch and a 30-minute break.

\section{Results}

\subsection{Analyses of the times and methods}

\subsubsection{Manual harvesting}

The manual harvesting process presents all the stages described in Table 1, beginning with fruit harvesting using the ladder and placing them into a bag with a false clamped bottom, and finishing by moving the ladder and going to the next tree. The mean 
duration of the harvest cycle in the studied population is of 16.3 minutes.

The duration of the harvesting stages and its frequency have a high variance between pickers and the type of orchard being harvested, mainly in regards to moving the ladder and the unloading the bag. The stages from manual harvesting that present the longest duration in the cycle are, "picking fruits on a ladder" with $49 \%$ and the "unloading the bag" with $17 \%$. Those two phases also have the highest number of repetitions from the manual harvesting, 120 and 160 per day, respectively.

Table 1

Lenght and Frequency of the cycles observed for the six pickers of manual harvesting

\begin{tabular}{lccc} 
& $\begin{array}{l}\text { Average } \\
\text { time per } \\
\text { tree }\end{array}$ & $\begin{array}{l}\text { Fre- } \\
\text { quency } \\
\text { per tree }\end{array}$ & $\begin{array}{l}\text { Frequency } \\
\text { per day }\end{array}$ \\
\hline $\begin{array}{l}\text { Picking fruits } \\
\text { on a ladder }\end{array}$ & $480 \mathrm{sec}$ & 6 & 120 \\
\hline $\begin{array}{l}\text { Picking fruits } \\
\text { without a } \\
\text { ladder }\end{array}$ & $120 \mathrm{sec}$ & 4 & 80 \\
\hline $\begin{array}{l}\text { Unloading } \\
\text { the bag }\end{array}$ & $168 \mathrm{sec}$ & 8 & 160 \\
\hline $\begin{array}{l}\text { Moving the } \\
\text { ladder }\end{array}$ & $96 \mathrm{sec}$ & 6 & 120 \\
\hline $\begin{array}{l}\text { Picking from } \\
\text { the ground }\end{array}$ & $108 \mathrm{sec}$ & 2 & 40 \\
\hline $\begin{array}{l}\text { Moving to the } \\
\text { next tree }\end{array}$ & $6 \mathrm{sec}$ & 1 & 20 \\
\hline
\end{tabular}

\subsubsection{Semi-mechanized harvesting}

Besides separating the cycle stages presented in Table 2, the semi-mechanized harvesting can also be organized as harvesting on top of the platform and at the bottom, which are simultaneously performed. The first one has the participation of four workers executing the task of "picking on the platform" to "moving the platform"; now on the bottom one, two pickers participate executing the tasks of "picking from the ground" to "replacing the bin". In total there are six pickers and one tractor driver guiding the machine.

The definition of the occupation positions is done by the pickers at the beginning of the day, but making sure that everyone performs each one of the stages. However there is no established rotation with schedules set to change position, it works according to the physical exhaustion at the work post.

To harvest a tree, it is necessary to repeat the stage "Moving the platform" twice according to Table 2, so that the guardrail device can attain the full range of harvested fruits. The platforms can only get a limited approximation to the tree due to the size of their guardrails and the risk of broken branches, which imposes the use of hooks to reach the farthest fruits.

The data presented in Table 2 refer to the mean times and the frequency of each picker performing the semi-mechanized harvesting stages.

Table 2

\begin{tabular}{|c|c|c|c|}
\hline \multicolumn{4}{|c|}{$\begin{array}{c}\text { Length and Frequency of the cycles observed in each of the six } \\
\text { pickers from the semi-mechanized harvesting }\end{array}$} \\
\hline & $\begin{array}{l}\text { Average } \\
\text { time } \\
\text { per tree }\end{array}$ & $\begin{array}{l}\text { Average } \\
\text { frequency } \\
\text { per tree }\end{array}$ & $\begin{array}{l}\text { Average } \\
\text { frequency } \\
\text { per day }\end{array}$ \\
\hline $\begin{array}{l}\text { Picking on the } \\
\text { platform }\end{array}$ & $136 \mathrm{sec}$ & 2 & 40 \\
\hline $\begin{array}{l}\text { Picking with a } \\
\text { hook }\end{array}$ & $78 \mathrm{sec}$ & 2 & 40 \\
\hline $\begin{array}{l}\text { Emptying the } \\
\text { boxes in the } \\
\text { conveyor belt }\end{array}$ & $36 \mathrm{sec}$ & 2 & 40 \\
\hline $\begin{array}{l}\text { Moving the } \\
\text { platform }\end{array}$ & $38 \mathrm{sec}$ & 2 & 40 \\
\hline $\begin{array}{l}\text { Picking at the } \\
\text { bottom }\end{array}$ & $250 \mathrm{sec}$ & 2.5 & 50 \\
\hline $\begin{array}{l}\text { Unloading the } \\
\text { bag }\end{array}$ & $40 \mathrm{sec}$ & 2.5 & 50 \\
\hline $\begin{array}{l}\text { Replacing the } \\
\text { canvas bin }\end{array}$ & $10.2 \mathrm{sec}$ & variable & 4 \\
\hline
\end{tabular}

The harvesting at the bottom is similar to "picking without a ladder" and "picking from the ground" shown in the harvesting manual (see Table 1), the differences are the distance walked and frequency to empty the bag and the fruit distribution on the tree.

The harvesting at the bottom is normally the bottleneck in the semi-mechanized harvesting process since there is a lesser number of pickers on the ground $(33.33 \%)$ and a higher concentration of fruits in this area, whether due to the conditions of the orchard, or the amount of fruits dropped by the platform pickers. This is demonstrated with a higher frequency of concentrated repetitions in the harvesting at the bottom (see Table 2).

Thus, the mean length of semi-mechanized harvesting cycle is measured by the time spent in the harvesting stages at the bottom, which is five minutes per tree.

The semi-mechanized harvesting stages that present longer duration within the cycle are "picking at the bottom" with $42 \%$, "picking on the platform" with $23 \%$ and "picking with a hook" with $13 \%$. 
The task of "replacing the bin" is uncertain and does not happen each time the machine stops, or at each harvested tree.

\subsection{Number of postures}

The observed population executes different types and numbers of posture movements to accomplish the selection and removal of all the fruits from a tree. The quantification of postural movements undergoes the influence of several factors, such as the height of trees, the planted variety, the fruit range determined by the closeness of the ladder or the platform to the tree, and the use of harvesting equipments and tools.

For the same amount of boxes harvested per day, the comparative analysis of performed postural movements in the harvesting methods indicates a higher number of postural movements in manual harvesting, $29 \%$ more than in the platform, mainly in regards to the number of static postures and the use of grip-related muscles as shown in Table 3.

Table 3

Quantification and classification of postures per cycle, tree and day, for citrus picker in the manual and semi-mechanized harvesting

\begin{tabular}{lcccc}
\hline & \multicolumn{2}{c}{ Per tree } & \multicolumn{2}{c}{ Per day } \\
\hline Postures & Manual & $\begin{array}{c}\text { Semi- } \\
\text { mechanized }\end{array}$ & Manual & $\begin{array}{c}\text { Semi- } \\
\text { Mechanized }\end{array}$ \\
\hline $\begin{array}{l}\text { Dinamic } \\
\text { postures }\end{array}$ & 420 & 404 & 8400 & 8080 \\
\hline $\begin{array}{l}\text { Static } \\
\text { postures }\end{array}$ & 138 & 60 & 2760 & 1200 \\
\hline $\begin{array}{l}\text { Awkward } \\
\text { postures }\end{array}$ & 108 & 72 & 2160 & 1440 \\
\hline $\begin{array}{l}\text { Use of } \\
\text { grip- } \\
\text { related } \\
\text { muscles }\end{array}$ & 168 & 108 & 3360 & 2160 \\
\hline \begin{tabular}{l} 
Total \\
\hline
\end{tabular} & 834 & 644 & 16680 & 12880 \\
\hline
\end{tabular}

The use of grip-related muscles is linked to the grip movement and palm compression, made during the handling of materials. In manual harvesting, the ladder and the bag need to be handled at each sequence of the harvesting stages of a tree; in the semimechanized, the frequency of using a range tool (hook) and the box emptying is lower, which does not happen in all stages. The wrist and hand movement to remove the fruits from the tree is also in- cluded in this classification; however it does not interfere with the amount, since it is compared to the same production in both methods.

On the other hand, the presence of a higher number of static postures in the manual harvesting is related to the postures maintained by the lower limbs while balancing on the ladder; by the neck, mainly in extension and flexion to pick the highest and lowest fruits; and by the trunk during the bag loading and fruit picking off the ground.

Both static postures and the use of grip-related muscles appear in a higher percentage. They are present in all harvesting stages, in opposition to other postures participating in the manual harvesting cycle.

The awkward postures are found while unloading the bag and reaching the fruits, with trunk postures in strong flexion and arms above the shoulders. Many times the pickers take risky positions, especially to reach fruits, holding on to branches with part of the body suspended.

The use of a reaching tool in the semi-mechanized harvesting and a greater stability provided by the rail device reduces the need for awkward postures. In the manual harvesting there is an added difficulty in using the bag on the ladder, resulting in higher instability.

The higher number of dynamic postures in manual harvesting refers to carrying the bag to the bin and climbing up and down the ladder, tasks that are practically eliminated in the semi-mechanized harvesting, except for the unloading of the bag at the bottom. There is no use of a ladder in the platform, and the distance to the bin is significantly smaller, since it and the pickers stay on the same course, which is different from manual harvesting.

\section{Discussion}

\subsection{Works conditions}

The overuse of movements, mainly the griprelated ones, is involved in the development of repetitive strain injuries (RSI) and work-related musculoskeletal disorders. Not one the physical stress brought by a greater number of movements predisposes this, but also the work organization with the absence of specified breaks and payment by production. Attempts to minimize costs and improve work conditions in manual harvesting are found in literature, where a new bag model to storage fruits is pro- 
posed, with improvements to relieve the weight carried and to bring more comfort to the picker; another study [4] points to a modification on the ladder, with an enlarged base to reduce accidents due to instability, a common cause of falls in the citrus orchards.

In regards to the repeatability of the tasks, Tables 1 and 2 show a higher repetition frequency of stages in manual harvesting. However in the semi-mechanized harvesting, the activity cycles are shorter, since the period between the stopping of a machine and the beginning of a new sequence has an average of 144 seconds; in manual harvesting this gap between one sequence and another is 207 seconds on average.

An advantage of manual harvesting over the semimechanized one is to enable a higher leeway for workers to change their operating methods, since they can follow different sequences of the harvesting stages mentioned in Table 1. They may also regulate their breaks individually, which is not possible in the semi-mechanized harvesting, as the set of tasks and their variability are smaller, both on top of the platform and on the ground. Besides this, the breaks have to be regulated with the team.

In this initial scenario, it was observed that by implementing the platforms, the development of a work-related intensification process could be possible, which happens due to a higher physical and cognitive stress, aiming to increase or improve the results quantitatively and qualitatively [12].

Even with the risk of labor intensification, semimechanized harvesting appears as a viable alternative to improve working conditions in the citrus orchards, since it reduces the presence of two of the three major risk factors in agriculture [2]: the carrying of weight and the sustained flexion of the whole body. Furthermore it eliminates the main cause of accidents: the ladder.

To minimize the intensification process and to make the implementation of this harvesting support beneficial to all the producers and harvesters, it is required attention to the work organization. It involves work-break regulations, schedule adequacy and development of other tools to assist harvesting, mainly in regards to reaching the fruits and machine safety. In addition, payment by production must be evaluated since it could determine high cognitive and physical stress.

\subsection{Productivity}

In manual harvesting, as well as platform harvesting, two factors are important to meet the expected productivity. However these factors are more relevant in semi-mechanized harvesting as it demands specific characteristics.

Firstly is the type of orchard, where the trees must vary from two to three meters/height and the fruits must be concentrated at the plant's top and middle. Trees that are very tall are difficult to be reached and demand the use of a hook, which when is not correctly handled, drops the green fruits and injures the next crop. On the other hand the fruit distribution at the bottom overloads the ground pickers, and delays the machine's operation.

Secondly is the team formation. After three months of testing with platforms and high rotation of pickers, an adaptation period varying from two weeks to two months, a more adequate worker profile for this kind of harvesting method was observed. Those are workers with a production ranging from three to five bins/day and with teamwork motivation.

As the work is paid according to production, many pickers felt harmed when having to share the daily production with others, which made it difficult to set up a team.

To minimize these problems, the workers' performance was accompanied by applying a bonussystem for goals accomplished, and teamwork training was implemented to work on top of the platform.

After the trial period until the end of harvesting, the machine managed to increase the income of the pickers up to $60 \%$; however those with a performance over the range of three to five bins/day had their productivity on the platform reduced. Studies confirm the ability to increase workers' efficiency with the use of platforms $[3,11]$.

Nevertheless, in the orchards of Florida (USA), the second largest orange juice producer in the world, a low use of this harvesting system was observed, since production increase was not significant relevant to enabling the cost of implementing a platform harvesting system [11].

In Brazilian orchards the data collected in this study showed compatibility in implementation costs and the efficiency obtained, with an investment return within one to three years, enabling the use of this platform harvesting system.

\section{Conclusion}

Thus, the implementation of this harvesting device in orchards managed to join increased productivity and improved working conditions, by providing more 
comfort to orange pickers. This occurred through reducing the walking frequency and distance to the bin carrying weight, and eliminating harvesting on top of the ladder, bringing with it less physical stress during working hours and greater harvesting safety, consequently reducing accident rates.

Although these data are promising in indicating a method that best aggregates profitability and workers' health, the process of implementing platforms must be monitored. Other variables must be analyzed, taking into account all work load elements, in order to have a complete guidance concerning the adoption of a method that benefits both producers and pickers.

The study of cognitive stress must also be considered, since the inclusion of a new device and team work brings new demands. This way the objectives will be achieved within the work conditions established by companies.

\section{Acknowledgments}

We appreciate the support from FAPESP, the citrus pickers who participated in the study, as well as the producers who allowed us to carry out visits in the orchards.

\section{References}

[1] A.E. Lopes, A.M. Emídio, S.C.T. Mafra, L.C.C. Salomão, N.R. Souza and R.C.P. Silva, Aplicação da Análise Ergonômica do Trabalho (AET) no Processo de Colheita de Citros: o caso da sacola colhedora. Availabe at: http://www.ichs.ufop.br/conifes/anais/SCS/scs0402.htm. Acessed: 07/20/2011.
[2] F.A. Fathallah, Musculoskeletal disorders in labor-intensive agriculture, Applied Ergonomics 41 (2010), 738 - 743.

[3] G.E. Coppock and P.J. Jutras, An investigation of the mobile picker's platform approach to partial mechanization of citrus fruit picking, Florida State Horticultural Society (1960), 258 263.

[4] I.M. Corrêa, R.C. Mello, R.Y. Yamashita and H.H. Ramos, Modificação de escada visando a melhoria da segurança na colheita manual de citros, Revista Brasileira Agrociência 15 (2009), $109-114$.

[5] J.P. Molin and L.S. Mascarin, Colheita de Citros e Obtenção de Dados para Mapeamento da Produtividade, Engenharia Agrícola 27 (2007), 259 - 266.

[6] K.F. Sanders, Orange harvesting systems review, Biosystems Engineering 90 (2005), 115 - 125.

[7] L.K. Smith, E.L. Weiss and D. Lehmkuhl, Brunnstrom's Clinical Kinesiology, ed., Manole, São Paulo, 1997, pp. 209 - 257.

[8] L. McAtammey and E.N. Corlett, RULA: a survey method for the investigation of work-related upper limb disorders, Applied Ergonomics 24 (1993), 91- 99.

[9] M.G. Valle, Cadeias inovativas, redes de inovação e dinâmica tecnológica da citricultura no Estado de São Paulo, Ph.D. Dissertation, Universidade Estadual de Campinas, 2002.

[10]R. Campos, A contribuição da citricultura paulista para o desenvolvimento das organizações em redes e da biotecnologia brasileira, Ph.D. Dissertation, Universidade Estadual de Campinas, 2004.

[11]R. Ehsani and S. Udumala, Mechanical harvesting of citrus: an overview, Engineering \& Technology for a Sustainable World (2010).

[12] S. Dal Rosso, Mais trabalho! A intensificação do trabalho na sociedade contemporânea, ed., Boitempo Editorial, São Paulo, 2008, pp. $19-43$ 